\title{
HIV Related Stigma Among People Living with HIV and AIDS in Limbe Health District, Cameroon
}

\author{
Ngwi Constance Tamungang ${ }^{1}$, Nde Fon Peter $^{1}$, Ndeso Sylvester Atanga ${ }^{2}$, Mary Bi Suh Atanga ${ }^{3}$ \\ ${ }^{1}$ Department of Public Health \& Hygiene, Faculty of Health Sciences, University of Buea, Buea, Cameroon \\ ${ }^{2}$ Department of Nursing and Allied Health science, St Monica University, Buea, Cameroon \\ ${ }^{3}$ Department of Nursing/Midwifery, Faculty of Health Sciences, University of Bamenda, Bamenda, Cameroon
}

Email address:

maryatanga@gmail.com (M. B. S. Atanga)

To cite this article:

Ngwi Constance Tamungang, Nde Fon Peter, Ndeso Sylvester Atanga, Mary Bi Suh Atanga. HIV Related Stigma Among People Living with HIV and AIDS in Limbe Health District, Cameroon. American Journal of Life Sciences. Vol. 8, No. 1, 2020, pp. 1-8.

doi: 10.11648/j.ajls.20200801.11

Received: December 6, 2018; Accepted: December 25, 2018; Published: March 23, 2020

\begin{abstract}
The background to thr article is that, the Human Immuno-deficiency Virus (HIV) - related stigma tends to create a vicious cycle of fear, ignorance, mistrust, misinformation, denial and self-isolation, which tend to further spread the virus because stigma affects the way people will take their treatment. The objective of this study was to assess the forms of stigma, and determine the role of stigma and other factors among HIV and the Acquired Immuno-Deficiency Syndrome (AIDS) patients on Anti- Retroviral Therapy (ART) in Limbe Health District. For the method, a cross-sectional design with a sample size of 389 was used. Interviewer- administered questionnaire was used to collect data from HIV and AIDS patients belonging to HIV support groups in Limbe Health District found at the treatment centre of the Limbe Regional Hospital. Data was collected on socio-demographic characteristics of respondents, forms of stigma and factors in association. Data was analyzed using STATA version 7.0. Results have shown that in all, stigma was experienced by $76.7 \%$ respondents. Among this group, self-stigma was experienced by $95 \%$ of the respondents while $28 \%$ experienced external stigma. Majority of respondents (92.8\%) admitted it was not easy to disclose their status, $7.2 \%$ felt dirty while $20.05 \%$ felt guilty of contracting HIV. Association of overall stigma with adherence to treatment showed no statistical significance, however respondents who did not experience self-stigma were more adherent $(76.9 \%)$ than those who experienced overall stigma $(71.01 \%)$. It can thus be concluded that people living with HIV/AIDS (PLWHA) belonging to HIV support groups in LHD experienced both internalized and external stigma, with the former experienced by almost all the respondents. Although stigma was not significantly associated with adherence to treatment, the very high level of internalized stigma warrants the implementation of stigma reduction measures.
\end{abstract}

Keywords: HIV/AIDS, Stigma Experiences, Effects

\section{Introduction}

The stigmatization of people living with HIV and AIDS (PLWHA) tends to create a vicious cycle of "socially shared ignorance, fear, mistrust, misinformation, denial which further spread the disease" [1]. This study was out to determine the forms of HIV-related stigma experienced by HIV patients taking treatment at a health district.

The National AIDS Control Committee (NACC) estimates that 141 HIV new infections are diagnosed daily in Cameroon, giving an average of six infections per hour. As concerns the mode of transmission, $90 \%$ of transmission is through sexual contact, $6 \%$ by mother-to-child transmission and $4 \%$ by blood and other means [2].

According to the Joint United Nations Programme on HIV/AIDS (UNAIDS), continued stigmatization and the resulting discrimination of PLWHA has created numerous barriers in preventing further infections, providing further care, support and treatment of PLWHA [3]. HIV-related stigma and discrimination is defined as "a process of devaluation of people either living with or associated with HIV and AIDS. While discrimination follows stigma and is the unfair and unjust treatment of an individual based on his 
or her real or perceived HIV status [4]". Furthermore, Goffman defines stigma as "an attribute that is deeply discrediting and that reduces the bearer from a whole and usual person to a tainted, discounted one [5]".

HIV-related stigma is due to many factors including; lack of understanding of the disease, believe that it is transmitted through irresponsible life styles, lack of access to treatment and the believe that it leads to death [6]. Stigma is generally associated to sexuality, gender, race and ethnicity and class. Sexual stigma is very common because HIV is mainly transmitted sexually, and in most parts of the world, the disease first affected people whose life style was questionable. This included homosexuals, prostitutes, intravenous drug users etc. Thus HIV is seen as a disease of the people who are promiscuous, or living a sexual deviant life style [7]. This probably explains why HIV and AIDS is seen "as death, as horror, as punishment, as guilt, or as shame", AIDS metaphors which "have exacerbated these fears thereby reinforcing and legalizing stigmatization and discrimination [7].

In Cameroon, both external and self-stigma is very common. Due to this, some HIV positive individuals isolate themselves from others, denying themselves the right to health care and even life because of fear of prejudice of others. Some even conceal taking the ART from their family members thereby leading to non-adherence and eventually leading to drug resistance [8]. A study carried out by Jacobi et al (2013) in Buea revealed that about half of the PLWHA interviewed suffered from stigmatization and discrimination mainly in the form of gossiping and verbal insult. Meanwhile about $50 \%$ felt ashamed and guilty of being HIV positive [9].

Equally important is the fact that the shame of living with HIV referred to as internalized or self-stigma may prevent PLWHA from seeking counseling, treatment, support services and even from exercising their rights such as going to work or attending school. This may often result to serious psychological influence on them leading to self-denial, blame, depression and self-imposed isolation [10].

Furthermore it is documented that HIV-related stigma has a negative impact on life satisfaction and the quality of life. It is associated with poorer mental outcomes, reduced selfesteem, reduced self-efficacy and decrease adherence to therapy [11]. In Vietnam for instance, stigmatizing community attitude towards PLWHA has profound consequences on them as it leads to internal stigma, selfisolation, lower self-esteem, and non-disclosure of HIV status. This has acted as a major barrier to seeking health care, adherence to therapy thereby leading to further transmission of the virus [12].

\subsection{Statement of Problem}

HIV stigma and discrimination in the health facilities may result to PLWHA not being able to access adequate prevention, care and treatment services [24]. According to UNAIDS, stigmatizing and discriminatory actions directed at PLWHA violates their fundamental human right to freedom from discrimination. It also lead to the violation of their other rights such as "rights to health, dignity, privacy, equality before the law, and freedom from inhuman, degrading treatment or punishment" [25]. Evidence also shows that stigma can become internalized by the patient and this can seriously affect physical and mental health. Internalized AIDS stigma can play a crucial role in the wellbeing as well as the distress suffered by AIDS patients [26]. Based on these, this study on experiences of internalized or self stigmatized among PLWHA at the study site.

\subsection{Objectives}

1. Assess the common forms of stigma experienced by PLWHA who were members of HIV support groups in Limbe Health District.

2. Determine the association between stigma and people accepting to take treatment among PLWHA who were members of HIV support groups in Limbe Health District.

3. Identify who and what are the main causes of stigma among PLWHA who were members of HIV support groups in Limbe Health District.

\section{Materials and Methods}

A descriptive cross-sectional and analytical study was conducted. The study setting was in an urban health facility. Eligible participants were HIV and AIDS patients who were initiated on antiretroviral therapy and were members of HIV support groups. The target population was made up of PLWHA, aged 21 years and above, who were HIV/AIDS positive and were on treatment.

A non-probability convenient sampling technique was used to recruit participants. The eligible participants who were available and accepted to take part in the study by signing the consent form were interviewed. This process continued until the sample size was reached. A standard structured interviewer administered questionnaire was used to collect data.

A sample size calculation formula that was used considered the estimation a single population proportion for a cross-sectional study of an infinite population.

$$
n=\frac{z^{2} p(1-p)}{d^{2}}
$$

Where $n=$ sample size

$\mathrm{z}=$ is the standard deviation in normal life which becomes 1.96 , using a $95 \%$ confidence interval

$\mathrm{p}=$ assumed proportion ofnon stigmatized $50 \%=0.5$

$\mathrm{d}=$ margin of error tolerated at $5 \%=0.05$

Computing in the formula gave:

$$
n=\frac{1.96^{2} * 0.5(1-0.5)}{0.05^{2}} \mathrm{n}=384
$$

A standard structured questionnaire designed to meet the objectives was used in data collection. It assessed whether respondents experienced stigma, and the forms of stigma. Internalized or self-stigma was assessed using the Internalized 
AIDS-Related Stigma Scale adapted and validated by Kalishman from the World Health Organization (WHO) Generic Tools for operational research [13], The Internalized AIDS-Related Stigma Scale is a structured screening tool with 6 items for the assessment of HIV related self-stigma and concealment of HIV status. To simplify administration, the questions were responded to dichotomously as 1= "Agree", and $0=$ "Disagree". This gave a stigma score ranging from 0-6 and if the respondent accepted that she had feelings of shame or worthlessness for example, she was considered as experiencing self-stigma [14, 15]. Enacted or external stigma was also measured using the WHO generic Tools for Operational Research [14]. It consists of 15 items focusing on physical assault, verbal abuse and abandonment of the HIV victim. Data was collected on a face-to-face administration of the questionnaire. Data collection was health facility and support group based. HIV support groups were visited during their meeting days for those who could be met at the health facility. After explaining the study and its purpose, informed consent was sought individually from members before administering the questionnaire. Data was analyzed using the statistical software programme STATA version 7. Administrative and ethical clearances were obtained from the Institutional Review Board of the Faculty of Health Sciences of the University of Buea and the health administrative structures of the region.

\section{Results}

Three hundred and eighty nine (389) correctly filled questionnaires were received and used for Out of a total of 389 participants who took part in this study the majority (69.41\%) were female. One hundred and three $(26.48 \%)$ respondents were unmarried, $61.7 \%$ were married, $8.23 \%$ were divorced and $3.6 \%$ were widows or widowers. Twenty-one (5.4\%) of the participants had no formal education, $32.39 \%$ attended primary education, the majority (53.98\%) attended secondary education, while $8.23 \%$ had been to the university. The participants' age ranged from 21 years to more than 50 years, with the age bracket 31- 40 years being the modal age range. Table 1 also describes the religious, residential, occupational status, food sufficiency and transport means of study participants to HIV treatment centre to receive their ARVs. A large majority of participants $(96.66 \%, \mathrm{n}=376)$ were Christians, only $4(1.03 \%)$ were Muslims, while $9(2.31 \%)$ had no religion. Residential distribution of participants shows that as many as $324(83.29 \%)$ lived in Limbe Health District (LHD -Urban) and 65 (16.71\%) live out of Limbe Health District (rural) and only came to attend HIV support group meetings and refill their ARVs. As concerns participant's occupational status, $38.8 \%$ were unemployed while $61.18 \%$ were employed or had something doing which raises them income. Respondents were also assessed on food sufficiency. More than half (63.24\%) reported that they had food sufficiency in the one month prior to the interview, $33.16 \%$ sometimes had food insufficiency, $2.31 \%$ participants often had difficulty feeding themselves while $1.29 \%$ always had food shortage.

The participants were also assessed on the transport means, length of time spent to treatment centre, transport cost to treatment centre and the length of time on ART. These were assessed because they might have implications on ART adherence in the long run.

The study participants used various transport means to the HIV Treatment Centre at the Limbe Regional Hospital where all of them receive their ARVs. More than half $(60.41 \%, n=235)$ went there by car, $34.7 \%(\mathrm{n}=135)$ by motor cycle and only $4.9 \%$ $(n=19)$ went there on foot. The mean time spent to reach the treatment centre was 31 minutes, with standard deviation (SD) of 38.71. The lowest and highest time spent was two minutes and three hours 10 minutes respectively.

Also the mean transport cost spent by the participants to and fro the HIV Treatment Centre was 1,197FCFA with SD of 1,583. The least transport cost was 0 FCFA (those who trekked); while some participants spent as much as 10,000 FCFA just to refill their ART each month.

As concerns length of time on ART, the least time was 6 months and the highest time was 15 years, giving a mean time of 4.9 with a SD of 3.11. Table 1 below shows the sociodemographic characteristics of the study participant.

Table 1. Distribution of participants according to socio-demographic variables.

\begin{tabular}{|c|c|c|c|}
\hline Variable & & Freq. $(\mathrm{N}=389)$ & Percent \\
\hline \multicolumn{4}{|l|}{ Gender } \\
\hline & Female & 270 & 69.41 \\
\hline & Male & 119 & 30.59 \\
\hline \multicolumn{4}{|c|}{ Marital status } \\
\hline & Unmarried & 103 & 26.48 \\
\hline & Married & 240 & 61.7 \\
\hline & Divorced & 32 & 8.23 \\
\hline & Widow & 14 & 3.6 \\
\hline \multicolumn{4}{|c|}{ Educational level } \\
\hline & None & 21 & 5.4 \\
\hline & Primary & 126 & 32.39 \\
\hline & Secondary & 210 & 53.98 \\
\hline & University & 32 & 8.23 \\
\hline \multicolumn{4}{|l|}{ Age } \\
\hline & $21-30$ & 45 & 11.57 \\
\hline & $31-40$ & 164 & 42.16 \\
\hline & $41-50$ & 128 & 32.9 \\
\hline & $>50$ & 52 & 13.37 \\
\hline \multicolumn{4}{|l|}{ Religion } \\
\hline & None & 9 & 2.31 \\
\hline & Christianity & 376 & 96.66 \\
\hline & Islam & 4 & 1.03 \\
\hline \multicolumn{4}{|l|}{ Residence } \\
\hline & Out of LHD & 65 & 16.71 \\
\hline & LHD & 324 & 83.29 \\
\hline \multicolumn{4}{|c|}{ Occupation } \\
\hline & Unemployed & 151 & 38.8 \\
\hline & Employed & 238 & 61.18 \\
\hline \multicolumn{4}{|c|}{ Food need } \\
\hline & Never lack & 246 & 63.24 \\
\hline & Sometimes & 129 & 33.16 \\
\hline & Often & 9 & 2.31 \\
\hline & Always & 5 & 1.29 \\
\hline \multicolumn{4}{|c|}{ Transport means } \\
\hline & On foot & 19 & 4.88 \\
\hline & Motorcycle & 135 & 34.7 \\
\hline & Car/vehicle & 235 & 60.41 \\
\hline
\end{tabular}


For forms of stigma, overall stigma was experienced by $76.7 \%$ of the respondents. The respondents experienced both internalized and external stigma.

For experiences of internalized or self-stigma, self-stigma was experienced by a large majority of the respondents. Three hundred and seventy-one (95\%) experienced selfstigma as shown on Figure 1.

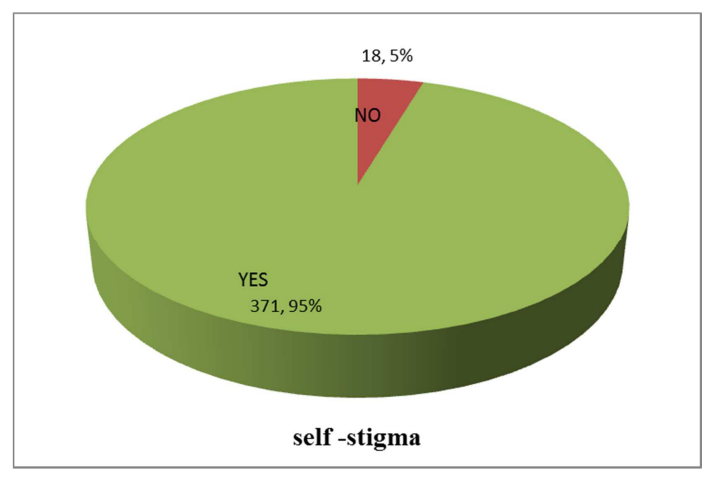

Figure 1. Distribution of participants according to self-stigma.

With regards to aspects of experiences of self-stigma, an overall, $92.8 \%$ of respondents agreed that it was not easy to disclose their HIV status, $7.2 \%$ agreed that being HIV positive made them feel dirty, $20.05 \%$ had feelings of guilt, $19.79 \%$ felt ashamed, $21.59 \%$ felt worthless while $83.8 \%$ actually hide their HIV positive status. Different question items represented issues on internalized stigma (Table 2).

Table 2. Distribution of participants according to various items of internalized stigma.

\begin{tabular}{lll}
\hline Items & Frequency $(\mathbf{N})$ & Percentage \\
\hline & \\
It is easy to tell people you are HIV positive & \\
Disagree & 361 & 92.80 \\
Agree & 28 & 7.20 \\
& \\
Being HIV positive makes you feel dirty & \\
Disagree & 361 & 92.80 \\
Agree & 28 & 7.20 \\
& \\
You feel guilty that you are HIV positive & \\
Disagree & 311 & 79.95 \\
Agree & 78 & 20.05 \\
& \\
You are ashamed that you are HIV positive & \\
Disagree & 312 & 80.21 \\
Agree & 77 & 19.79 \\
& \\
You sometimes feel worthless because you are HIV positive \\
Disagree & 305 & 78.41 \\
Agree & 84 & 21.59 \\
& & \\
You hide your HIV status from others & 16.20 \\
Disagree & 63 & 83.80 \\
Agree & 326 & \\
\hline
\end{tabular}

The association of self-stigma with socio-demographic variables was analyzed and summarized as on table 3 below. Results shows that $94.81 \%$ female and $96.64 \%$ male respondents felt stigmatized by being HIV seropositive.
Regarding marital status, $94.17 \%$ of unmarried, $96.67 \%$ married, 93.75\% divorced and $85.71 \%$ widowed were stigmatized by their HIV status. This association was however not statistically significant. The relationship between self-stigma and age of respondents also show no statistical significant. However, those above 50 years felt lesser self-stigma (90.38\%), compared to $93.33 \%$ for the age group 21-30 years; $95.73 \%$ for those aged $41-50$ years; and $97.66 \%$ for those aged $41-50$. With regards to educational level, all with non-formal education (100\%), 94.44\% of those with primary education, $95.71 \%$ with secondary education and $93.75 \%$ of those with tertiary education experienced selfstigma. Also relationship between self-stigma and religious affiliation show no statistical significance. All Muslims $(100 \%)$ and all those who reported having no religion (100\%) experienced self-stigma as against $95.21 \%$ of Christians. Likewise the association of stigma with occupational status shows that $96.03 \%$ of unemployed and $94.96 \%$ employed respondents experienced self-stigma. Place of residence had, $95.38 \%(n=62)$ of respondents who lived out of Limbe Health District (rural) and $95.37 \%(n=309)$ of those within Limbe Health District (Urban) felt stigmatized. As realized, the association between HIV self-stigma and the sociodemographic characteristics of respondents show no statistical significance (Table 3).

Table 3. Association of HIV self-stigma with participant's sociodemographic variables.

\begin{tabular}{|c|c|c|c|}
\hline \multirow{2}{*}{ variable } & \multicolumn{2}{|c|}{ stigmatized } & \multirow{2}{*}{ p-value } \\
\hline & NO & YES & \\
\hline \multicolumn{4}{|l|}{ Gender (N,\%) } \\
\hline Female & $14(5.19)$ & $256(94.81)$ & \multirow{2}{*}{0.430} \\
\hline Male & $4(3.36)$ & $115(96.64)$ & \\
\hline \multicolumn{4}{|c|}{ Marital status (N,\%) } \\
\hline Unmarried & $6(5.83)$ & $97(94.17)$ & \multirow{4}{*}{0.222} \\
\hline Married & $8(3.33)$ & $232(96.67)$ & \\
\hline Divorced & $2(6.25)$ & $30(93.75)$ & \\
\hline Widowed & $2(14.29)$ & $12(85.71)$ & \\
\hline \multicolumn{4}{|l|}{ Age bracket } \\
\hline 21-30 YRS & $3(6.67)$ & $42(93.33)$ & \multirow{4}{*}{0.179} \\
\hline 31-40 YRS & $7(4.27)$ & $157(95.73)$ & \\
\hline 41-50 YRS & $3(2.34)$ & $125(97.66)$ & \\
\hline$>50 \mathrm{YRS}$ & $5(9.62)$ & $47(90.38)$ & \\
\hline \multicolumn{4}{|c|}{ Level of education } \\
\hline None & $0(0.00)$ & $21(100.00)$ & \multirow{4}{*}{0.660} \\
\hline Primary & $7(5.56)$ & $119(94.44)$ & \\
\hline $2^{\text {ary }}$ high & $9(4.29)$ & $201(95.71)$ & \\
\hline University & $2(6.25)$ & $30(93.75)$ & \\
\hline \multicolumn{4}{|l|}{ Religion } \\
\hline None & $0(0.000$ & $9(100.00)$ & \multirow{3}{*}{0.760} \\
\hline Christian & $18(4.79)$ & $358(95.21)$ & \\
\hline Muslim & $0(0.00)$ & $4(100.00)$ & \\
\hline \multicolumn{4}{|l|}{ Occupation } \\
\hline Unemployed & $6(3.97)$ & $145(96.03)$ & \multirow{3}{*}{0.625} \\
\hline Employed & $12(5.04)$ & $226(94.96)$ & \\
\hline \multicolumn{3}{|l|}{ Residence } & \\
\hline Out of LHD & $3(4.62)$ & $62(95.38)$ & \multirow{2}{*}{0.996} \\
\hline LHD & $15(4.63)$ & $309(95.37)$ & \\
\hline
\end{tabular}


Looking at data on external or enacted stigma, there was a minimal existence of 109 (28\%) (Figure 2).

From the above figure, unlike self-stigma, fewer respondents experienced external stigma. Detailed result of various aspects of who and what showed stigma perpetuated by spouse or sex to be $15.94 \%$ while most respondents did not suffer stigma caused by their partner (84.06\%).

The response per item of external stigma caused by spouse or sexual partner is shown on Figure 3 below. Five point four percent $(5.4 \%)$ of the participants experienced physical assault from their partner after disclosing their HIV status, $10.54 \%$ were blamed for contracting HIV, 8.25\% were verbally abused, while $5.93 \%, 6.43 \%$ and $5.4 \%$ experienced divorce, were ignored and abandoned respectively by spouse.

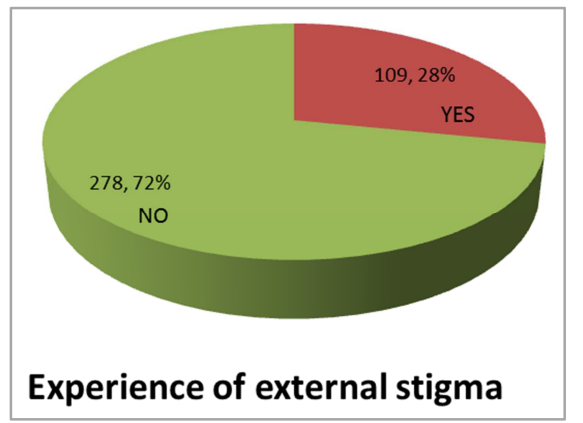

Figure 2. Distribution of respondents according to external stigma.

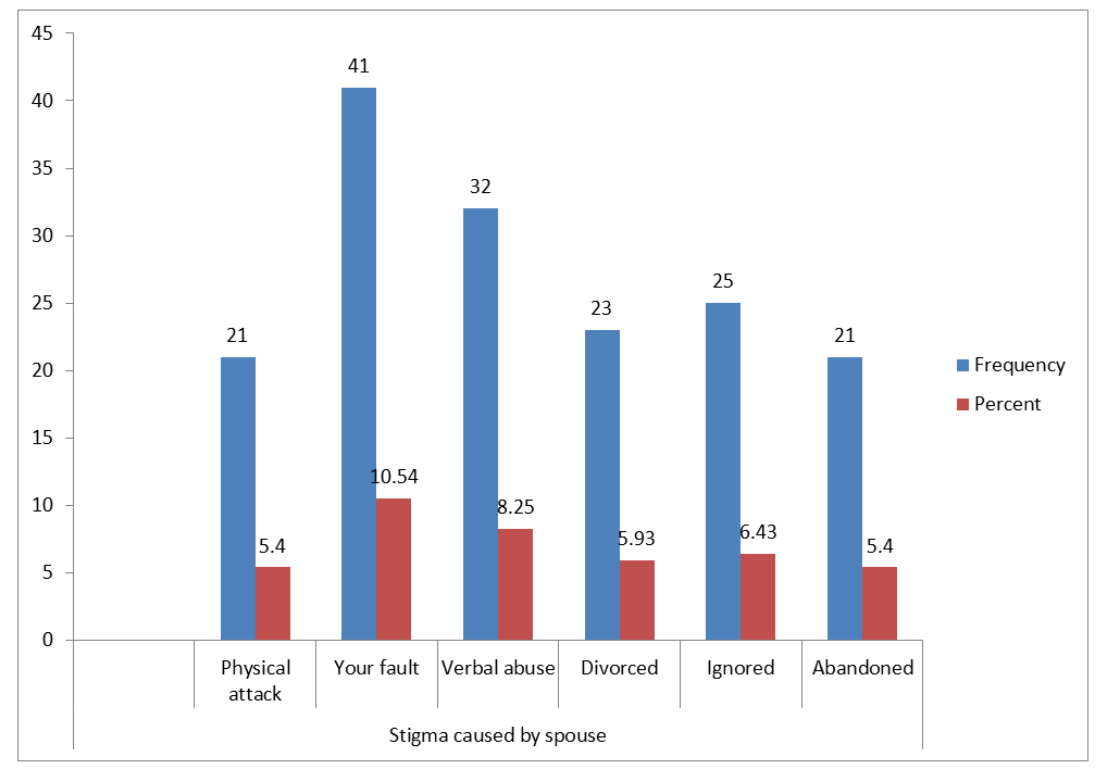

Figure 3. Distribution of participants per item of external stigma caused by spouse or sex partner

The experiences of external stigma caused by community and other family members and the results: that less than a quarter of the participants $22.62 \%$ experienced stigma from the community and other family members. Figure 4 depicts the response per item of external stigma caused by the community and other family members. The three aspects of external stigma suffered mostly by respondents from community and other family members were being gossiped about $(19.02 \%)$, blamed as being one's fault for contracting HIV (5.14\%) and verbal abuse (3.36\%).

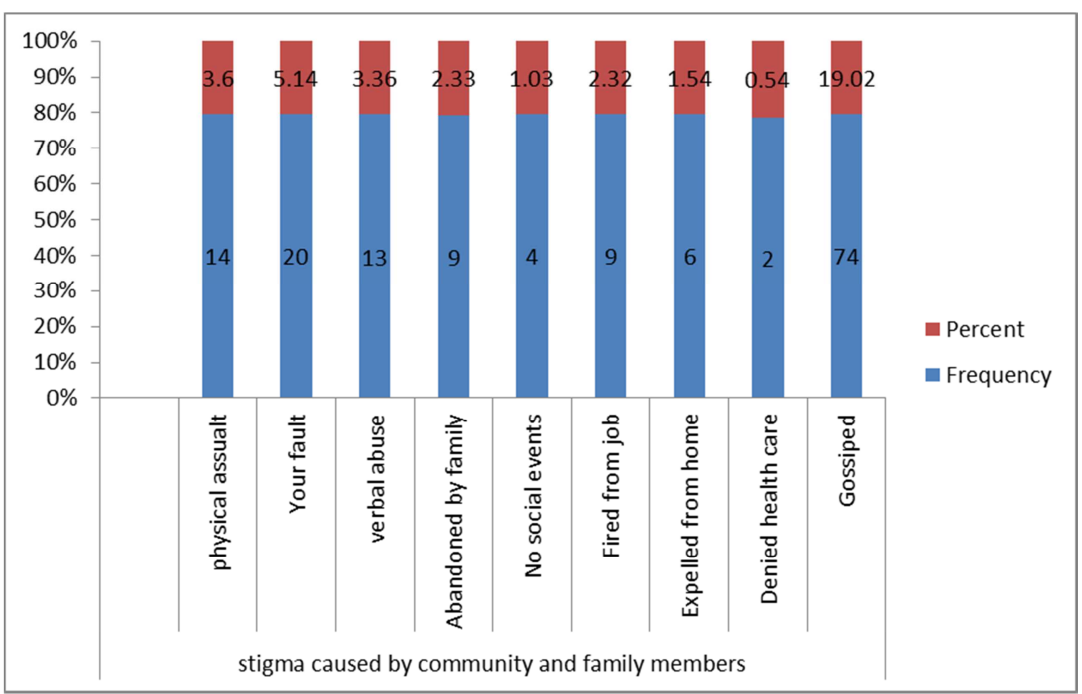

Figure 4. Distribution of participants according to stigma caused by community and other family members. 
An association between external stigma by spouse and socio-demographic data was established as below.

Gender: Result reveals that $26.05 \%$ of male respondents as compared to $11.48 \%$ of females were stigmatized by their spouse because of their HIV positive status. This difference was statistically significant (P-value $<0.01$ ). Comparing males to females, males were 2.72 times as likely as females to be stigmatized by their spouse. After adjusting for confounders (religion and residence), males were 2.94 times as likely as females to be stigmatized by their spouse.

Marital status: Also, $13.59 \%$ of unmarried respondents and $13.33 \%$ of married respondents were stigmatized by their spouse, meanwhile $50 \%$ of the divorced reported being stigmatized by their former spouse or sexual partner. $100 \%$ of widows/widowers reported no spousal stigmatization. This difference was not statistically significant.

Educational level: Concerning educational level, majority of respondents who felt stigmatized by spouse or partner were those with secondary education $(17.14 \%)$, followed by primary school leavers $(15.08 \%)$, while respondents with tertiary education $(12.50 \%)$ were the least stigmatized by their spouse or partner.

Religion: Concerning religion, $75 \%$ of Muslims, $15.16 \%$ of Christians and $22.22 \%$ of respondents without a religion reported stigmatization by spouse or sexual partner. This difference was statistically significant with a P-value of 0.0043 .
Comparing Christians to respondents without religion, Christians were 0.63 times as likely as those without a religion to be stigmatized by their spouse. After adjusting for confounders, Christians were 0.88 times as likely as those without a religion to be stigmatized by their spouse.

Comparing Muslims to respondents without a religion, Muslims were 10.5 times as likely to be stigmatized by their spouse. After adjusting for confounders, Muslims were 16.71 times as likely to be stigmatized by their spouse as respondents without a religion.

Residence: $24.62 \%$ of respondents living out of Limbe Health District and $14.20 \%$ of those living in Limbe Health District were stigmatized by their spouse or sexual partner. This difference was statistically significant (P-value 0.036).

Logistic regression gave an OR of 0.51 while multiple logistic regressions gave an aOR of 0.40 . This means that participants in LHD were 0.04 times as likely as participants out of LHD to be stigmatized by their spouse. The OR is less than one (1) which means that those living out of LHD experienced more stigma from their spouse.

Occupation: Association of internalized spousal stigma with participant's occupation was not statistically significant. Overall, $13.91 \%$ of unemployed and $17.23 \%$ of employed participants were stigmatized because of their HIV status. Table 4 below summarizes the association of external stigma by spouse/sexual partner with participant's socio-demographic characteristics.

Table 4. Association between external stigma by spouse and socio-demographic data.

\begin{tabular}{|c|c|c|c|c|c|c|c|}
\hline Variable & Yes $(\mathrm{N}, \%)$ & No $(\mathrm{N}, \%)$ & P-value & OR & aOR & P-value & $95 \%$ CI \\
\hline Gender & & & 0.000 & & & & \\
\hline Females & $31(11.48)$ & $239(88.52)$ & & ref & & & \\
\hline Males & $31(26.05)$ & $88(73.95)$ & & 2.72 & 2.94 & 0.000 & $1.65-5.26$ \\
\hline Marital status & & & 0.0767 & & & & \\
\hline Unmarried & $14(13.59)$ & $89(86.41)$ & & & & & \\
\hline Married & $32(13.33)$ & $208(86.67)$ & & & & & \\
\hline Divorced & $16(50.00)$ & $16(50.00)$ & & & & & \\
\hline Widow/widower & $0(0.000)$ & $14(100.00)$ & & & & & \\
\hline Level of education & & & 0.8926 & & & & \\
\hline None & $3(14.29)$ & $18(85.71)$ & & & & & \\
\hline Primary & $19(15.08)$ & $107(84.92)$ & & & & & \\
\hline Secondary & $36(17.14)$ & $174(82.86)$ & & & & & \\
\hline Tertiary & $4(12.50)$ & $28(87.50)$ & & & & & \\
\hline Age bracket & & & 0.6720 & & & & \\
\hline $21-30$ years & $9(20.00)$ & $36(80.00)$ & & & & & \\
\hline $31-40$ years & $22(13.41)$ & $142(86.59)$ & & & & & \\
\hline $41-50$ years & $22(17.19)$ & $106(82.81)$ & & & & & \\
\hline$>50$ years & $9(17.31)$ & $43(82.69)$ & & & & & \\
\hline Religion & & & 0.0043 & & & & \\
\hline None & $2(22.22)$ & $7(77.78)$ & & ref & & & \\
\hline Christians & $57(15.16)$ & $319(84.84)$ & & 0.63 & 0.88 & 0.881 & $0.17-4.65$ \\
\hline Muslims & $3(75.00)$ & $1(25.00)$ & & 10.5 & 16.71 & 0.053 & $1.0-288.9$ \\
\hline Residence & & & 0.036 & & & & \\
\hline Out of LHD & $16(24.62)$ & $49(75.38)$ & & ref & & & \\
\hline Within LHD & $46(14.20)$ & $278(85.80)$ & & 0.51 & 0.40 & 0.008 & $0.20-0.79$ \\
\hline Occupation & & & 0.383 & & & & \\
\hline Unemployed & $21(13.91)$ & 130 (86.09) & & & & & \\
\hline Employed & $41(17.23)$ & 197 (82.77) & & & & & \\
\hline
\end{tabular}




\section{Discussion}

In this study, the proportion of respondents who experienced internalized and enacted stigma, and the relationship between stigma and participants' sociodemographic variables was assed.

Overall stigma was $76.7 \%$. This finding is in contrast with the findings from South East Nigeria [16] where overall stigma was only $31.7 \%$. Between the two forms of stigma experienced, internalized or self-stigma was very high (95\%), while enacted stigma was experienced only by $28 \%$ of the respondents. This means that stigma is felt more internally than externally. This high level of internalized and low external stigma corroborates with a study carried out in Los Angeles in 2007 [17] which shows that internalized stigma was $89 \%$ and external stigma was $31 \%$. It differs from a study carried out in Nigeria in 2012 [1]which portray that only $37.1 \%$ of the respondents experienced self-stigma and up to $98 \%$ suffered from external stigma. Although the association of internalized stigma with socio-demographic variables was not statistically significant, this study reveals that increase in education was directly related to reduce selfstigma. Respondents with the highest level of education (tertiary education) experienced the least self-stigma (93.75\%) compared to $100 \%$ self-stigma among those without formal education. This could be as a result of better living and working conditions among people with higher education. This result is in consistent with a study carried out by Sekoni et al [ibid] which reveals that increase in level of education was associated with a reduction in self-stigma.

Only $28 \%$ of respondents experienced external stigma in this study. This low level of stigma is probably because majority of respondents $(83.80 \%)$ hide their HIV status from other people and $14.91 \%$ of them even admitted that their spouses were not aware of the fact that they were on ARV treatment. Result of external stigma also reveal that many of the respondents suffered from gossip, verbal abuse, were blamed for contracting HIV, physically assaulted, ignored and abandoned by their spouse. This is in conformity with a study carried out in Buea Cameroon by Jacobi et al [9] which shows that the major problem faced by PLWHA regarding stigmatization was gossiping, verbal abuse and abandonment. A statistically significant association was observed between external stigma caused by spouse with socio-demographic variables (gender, religion and place of residence) of respondents. Women $(11.48 \%)$ were less likely to be stigmatized by their spouse, while men $(26.05 \%)$ were more likely to be stigmatized by their spouse. This is evident as women are quick at accusing their spouse of infidelity and infecting them with the virus when their HIV result shows positive. Also Muslim respondents (75\%) experienced more stigma by spouse compared to only $15.16 \%$ Christians and $22.22 \%$ respondents without a religion. However no studies were found which separately related external stigma caused by spouse and that caused by community with sociodemographic variables. Most studies on internalized and external stigma $[1,18,19]$ only assessed the association between self-stigma and/or external stigma with sociodemographic variables.

Likewise the association of external stigma caused by spouse and by other community members with residence shows a statistical significant association (P-value 0.036 and 0.003 respectively). Respondents living out of LHD (rural) experienced more stigma from their spouse than those living in LHD (urban). Respondents out of LHD (rural) also experienced more stigma from community members compared to those living in LHD (urban). This may explain why some respondents travelled over three hours, spending as much as $10,000 \mathrm{FCFA}$ every month just to go to the HIV treatment centre at Limbe Regional Hospital for treatment refill, meanwhile there are other HIV treatment centres not very far from their residence. This finding corroborates with the finding of Nyblade L [7] which shows how people have tried to distant themselves from HIV by "not seeking care until extremely ill, grinding pills into powder to conceal medications from others and travelling far from home and local gossip to visit health providers". The public health implication is that despite the dramatic progress in HIV interventions, the social aspect of the disease such as stigma continues to threaten the emotional, psychological and physical welfare of PLWHA thereby reducing adherence level and affecting other areas of their life. As PLWHA are stigmatized upon by family and community members, this may encourage them to take their treatments in hiding and may skip some doses thereby leading to sub-optimal treatment with the resulting consequences on their health and to society as a whole.

\section{Conclusions}

PLWHA in Limbe Health District experience enormous self-stigma. Self and enacted stigma exist in the study population and affects the taking of treatment. Spouses and sex partners are also agents of stigma; and worse of all community and other family members have been found to be a source of stigma.

\section{Recommendations}

Self-stigma reduction interventions should be a priority among PLWHA and they should be educated on stigma reduction strategies during counseling sessions and HIV support group meetings.

General community sensitization is still required to reduce stigma by spouses, family and community members.

\section{References}

[1] Sekoni AO, Obidike OR, Balogun MR. Stigma, medication adherence and coping mechanism among people living with HIV attending General Hospital, Lagos Island, Nigeria. Afr J Prim Health Care Fam Med. 2012. Available from. 
[2] National AIDS Commission, Cameroon (NACC). The impact of HIV and AIDS in Cameroon through 2020. National AIDS Control Committee Cameroon; 2010.

[3] Aggleton, Peter, Wood, Kate, Malcolm, Anne. HIV-related stigma, discrimination and human rights violations. Case studies of successful progammees. UNAIDS; 2005.

[4] Nam SL, Fielding K, Avalos A, Dickinson D, Gaolathe T, Geissler PW. The relationship of acceptance or denial of HIVstatus to antiretroviral adherence among adult HIV patients in urban Botswana. SocSci Med 1982. 2008; 67 (2): 301-10.

[5] Goffman E. Stigma: Notes on the management of spoiled identity. Garden City NY: Anchor Books; 1963.

[6] Charles B, Jeyaseelan L, Pandian AK, Sam AE, Thenmozhi $\mathrm{M}$, Jayaseelan V. Association between stigma, depression and quality of life of people living with HIV/AIDS (PLHA) in South India - a community based cross sectional study. BMC Public Health. 2012; 12 (1): 463.

[7] Laura Nyblade. Can we measure HIV/AIDS-related stigma and discrimination? Current knowledge about quantifying stigma in developing countries. USAID; 2006.

[8] Mbuagbaw L, Thabane L, Ongolo-Zogo P, Yondo D, Noorduyn S, Smieja M, et al. Trends and determining factors associated with adherence to antiretroviral therapy (ART) in Cameroon: a systematic review and analysis of the CAMPS trial. AIDS Res Ther. 2012; 9 (1): 1-10.

[9] Jacobi CA, Atanga PNJI, Bin LK, Mbome VN, Akam W, Bogner JR, et al. HIV/AIDS-related stigma felt by people living with HIV from Buea, Cameroon. AIDS Care. 2013; 25 (2): 173-80.

[10] Stangl AL, Grossman CI. Global Action to reduce HIV stigma and discrimination. J Int AIDS Soc. 2013 http://www.ncbi.nlm.nih.gov/pmc/articles/PMC3834870/.

[11] Deribew A, HaileMichael Y, Tesfaye M, Desalegn D, Wogi A, Daba S. The synergy between TB and HIV co-infection on perceived stigma in Ethiopia. BMC Res Notes. 2010; 3 (1): 249.

[12] Pharris A, Hoa NP, Tishelman C, Marrone G, Chuc NTK, Brugha $\mathrm{R}$, et al. Community patterns of stigma towards persons living with HIV: A population-based latent class analysis from rural Vietnam. BMC Public Health. 2011; 11 (1): 705 .

[13] Reynolds, Lucy. HIV-related stigma Measures and Measurement Tools: Consultation with PLHIV to contribute to the development of common indicators. UNAIDS; 2010.

[14] WHO. HIV Testing, Treatment and Prevention: Generic Tools for Operational Research. Malta: WHO; 2009.

[15] Yuri Sasaki. Adherence to antiretroviral therapy (ART), selfstigma and depression among people living with HIV (PLWH) in rural Zambia. [Japan]: university of Tokyo; 2012.

[16] Okoli CI, Cleary SM. Socioeconomic status and barriers to the use of free antiretroviral treatment for HIV/AIDS in Enugu State, south-eastern Nigeria. Afr J AIDS Res. 2011. Available from: http://www.ajol.info/index.php/ajar/article/view/67144.

[17] Sayles JN, Wong MD, Kinsler JJ, Martins D, Cunningham WE. The Association of Stigma with Self-Reported Access to Medical Care and Antiretroviral Therapy Adherence in Persons Living with HIV/AIDS. J Gen Intern Med. 2009; 24 (10): $1101-8$

[18] Martinez J, Harper G, Carleton RA, Hosek S, Bojan K, Glum $\mathrm{G}$, et al. The Impact of Stigma on Medication Adherence Among HIV-Positive Adolescent and Young Adult Females and the Moderating Effects of Coping and Satisfaction with Health Care. AIDS Patient Care STDs. 2012; 26 (2): 108-15.

[19] Katz IT, Ryu AE, Onuegbu AG, Psaros C, Weiser SD, Bangsberg DR, et al. Impact of HIV-related stigma on treatment adherence: systematic review and meta-synthesis. J Int AIDS Soc. 2013. Available from: /pmc/articles/PMC3833107/ 